\title{
SEISMIC DESIGN OF STORAGE TANKS
}

\author{
M. J. N. Priestley ${ }^{1}$ J. H. Wood ${ }^{2}$ and B. J. Davidson ${ }^{3}$
}

\begin{abstract}
A study group of the New Zealand National Society for Earthquake Engineering has recently completed recommendations for the Seismic Design of Storage Tanks, in a form suitable to be used as a code by the design profession. The recommendations cover design criteria, loading, actions and details and are based on a consistant philosophy of serviceability under the design level earthquake. This paper provides a review of the study group's recommendations.
\end{abstract}

\section{INTRODUCTION}

The seismic performance of storage tanks is a matter of special importance, extending beyond the economic value of the tanks and contents. Without an assured water supply, uncontrolled fires subsequent to a major earthquake may cause substantially more damage than the earthquake itself, as occurred in the great 1906 San Francisco earthquake. Safe supplies of drinking water are also essential immediately following destructive earthquakes to avoid outbreaks of disease. Consequently, water supply reservoirs must remain functional after earthquakes. Failure of tanks containing highly inflammable petroleum products has frequently lead to extensive uncontrolled fires, as occurred, for example, following the Niigata and Alaska earthquakes of 1964. Spillage of toxic chemicals or liquified gases from damaged tanks could release dangerous liquids or gas clouds with disastrous effects in populous areas.

Damage to steel storage tanks in recent earthquakes includes 'elephantsfoot" buckling of bottom shell courses (Fig. I) (I), diamond-shaped buckling of tanks with very thin shells (Fig. 2) (2), failure of frangible joints between wall and cone roofs due to sloshing of liquids, failure of the tank support system for elevated tanks(3), foundation failure due to liquefaction of materials under tanks (4), fracture of wall/base-plate welds in tanks unrestrained or partially restrained against uplift(I), and fracture of piping connected to the tank (I)

Concrete tanks have also suffered significant damage. Many elevated concrete

1 University of California, San Diego; formerly University of Canterbury.

2 Ministry of Works and Development.

3 University of Auckland. reservoirs failed, or were severely damaged in the 1960 Chilean earthquake (5). This was particularly the case where the support system consisted of vertical columns circumferentially disposed, joined by one or more levels of circumferential beams (see Fig. 3). Failure of beam and column plastic hinges in these circular frames was common. Although ground-supported concrete tanks have not been extensively damaged, underground tanks have, as illustrated by Fig. 4 which shows damage to support columns and roof construction joints sustained by an underground concrete reservoir of the Balboa Water treatment plant in the 1971 San Fernando earthquake (1)

\section{In 1983 the New Zealand National}

Society for Earthquake Engineering set up a Study Group to produce recommendations for the seismic design of storage tanks(6). It was perceived that there was a real need for a unified approach to the problem, as existing codes for storage of water, petro-

chemicals and other substances were based on quite different principles, and included significant differences in basic requirements. The range of tanks covered by the codes was rather small and was inadequate for the sizes, shapes and support conditions commonly experienced in New Zealand. The recommendations were not in a form compatible with other relevant New Zealand codes.

The intention of the study group was to collate existing information, available in research papers and codes, and to produce uniform recommendations that would cover as wide a range of tank designs and contained materials as possible. Design philosophy was to be clearly stated, as this was notable lacking in existing documents. It was felt that sufficient existing information was available to provide the basis for detailed recommendations for the great majority of tank designs. The committee recognised that any involvement in basic research would delay the production of the 
final recommendations, and hence new material presented in the document is limited, though the manner of presentation has frequently been altered in the interests of clarity. Areas where it is felt that further basic research is needed are identified.

Three codes have commonly been considered, under different conditions, for the design of storage tanks in New Zealand. These are the New Zealand Loadings Code, NZS $4203(7)$, Appendix E of the American Petroleum Institute standard API-650(8), and a Ministry of Works and Development document, Seismic Design of Petrochemical Plants (9). Another standard of relevance is the American Waterworks Association document AWWA D-100(10).

The Loadings Code gives little guidance for the seismic analysis of storage tanks, but does specify design loads in terms of seismic zone, risk factor, and structural type factor. As some tanks will legally be described as buildings, NZS 4203 will be deemed to apply, and has been adopted for design in many cases. API-650-E has been widely used for design of petroleum storage tanks in New Zealand. This document is based on Housner's representation of the mechanical analogue(11), and an assessment of seismicity appropriate to the USA. The applicability to New Zealand seismicity is not clear, and many of the provisions are subject to some controversy. Some of these include lateral force coefficients for sloshing modes, recommended levels of damping, estimation of compressive stress in unanchored tanks, and general treatment of tank flexibility and buckling. Some of the API-650-E equations contain errors.

Tanks for New Zealand's recent major projects have generally been designed to the MWD-SDPP document (9). The seismic section of this code and its commentary are loosely based on API-650-E and the recommendations of the NZNSEE for seismic design of bridges (12). Some of the errors and omissions of API-650-E have been noted and corrected. However, some areas of controversy remain. For example, the shape of response spectra shown in Figs. 2.2 and 2.3 of SDPP do not represent typical earthquake characteristics at either very short periods ( $T<0.2 \mathrm{~s}$ ) or very long periods $(T>3.0 \mathrm{~s})$, being very conservative at both limits. Since it is these periods ranges that are of particular interest in the design of storage tanks, it is clear that economies of design may be possible from the adoption of more realistic spectra. In the period range $0.3 \mathrm{~s}<\mathrm{T}<1.0 \mathrm{~s}$, which is of relevance to flexible steel tanks, and elevated tanks, the SDPP spectra appear to be non-conservative.

None of the above codes provide information relevant to the special problems of concrete tanks, elevated tanks, tanks of unusual shape or excessive flexibility. Foundation problems are inadequately dealt with, and the overall problem of seismic risk and probability of failure are treated in simplistic fashion if at all. In NZS $4203^{(7)}$ the relationship between the risk factor $R$ (which varies between 1.0 and 2.0) and the expected probability of exceedence of the design earthquake is not stated. The SDPP document provides useful information on the suitable return period for specific design situations, but other codes do not address the problem. The design philosophy of existing codes is not clearly stated, particularly related to definition of performance criteria under the design loads.

The Recommendations attempt to produce a unified approach for the seismic design of storage tanks, regardless of materials or function, and to provide additional information to that already available in alternative sources. The information relaces only to the storage tanks themselves and their immediate fixings to pipelines, but not to pipeline design itself. Much useful design information on pipeline design is available in a recent ASCE publication(13).

The Recommendations are divided into six sections, covering general design principles, design loading, design actions, design criteria, foundations, and design details. Each section is presented in the form of code and commentary clauses for those who wish to adopt the recommendations. However, it must be recognised that the document produced by the society has no legal status unless adopted by some regulatory authority.

The remainder of this paper provides a brief overview of the different sections of the recommendations.

\section{SECTION 1 : GENERAL DESIGN PRINCIPLES}

Section 1 defines the intensity of the design-level earthquake, and also defines the performance criteria. The design-level earthquake is required to have an annual probability of exceedence, p, not greater than tabulated values, which depend on the importance of the storage facility, and the danger associated with failure of the facility. Design annual probabilities of exceedance range from 0.05 for minor farm storage tanks, down to 0.0002 for large tanks used for storage of highly flammable, toxic or explosive materials in urban areas.

It will be noted that annual probability of exceedence is used in preference to the more common average return rexiod of the design-level earthquake. This latter approach adopted by the NZNSEE study group on seismic design of bridges(12), and subsequently in the Ministry of Works and Development document on seismic design of petrochemical plants (19) implies that occurrence of the desiqn earthquake is independent of recent seismic activity. While this approach is certainly advisable for ground shaking of comparatively high annual probability of exceedence, say $\mathrm{p}>0.005$, it may be non-conservative where the site is close to a major active fault which is known not to have moved for a period approaching, or exceeding its average return period. Clearly in such cases, high intensity ground shaking of low $p$ value will be affected to some extent by the history of movement on any local major faults. As local seismicity and earthquake prediction methods become more refined, it will become increasingly relevant to describe risk in 


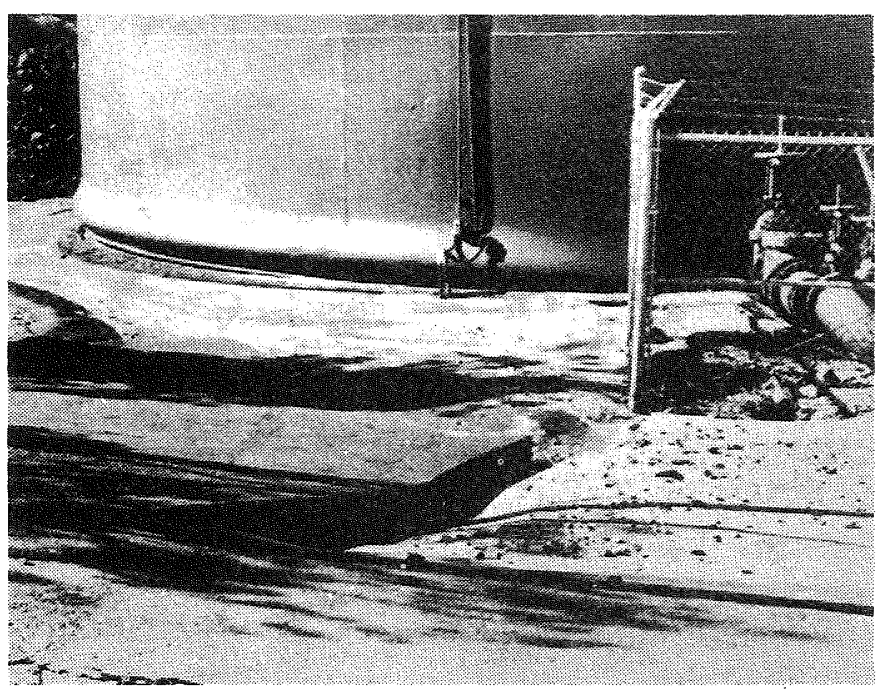

Fig. 1. 'Elephants Foot' Buckling and Piping Failure to Steel Water Tank (1)

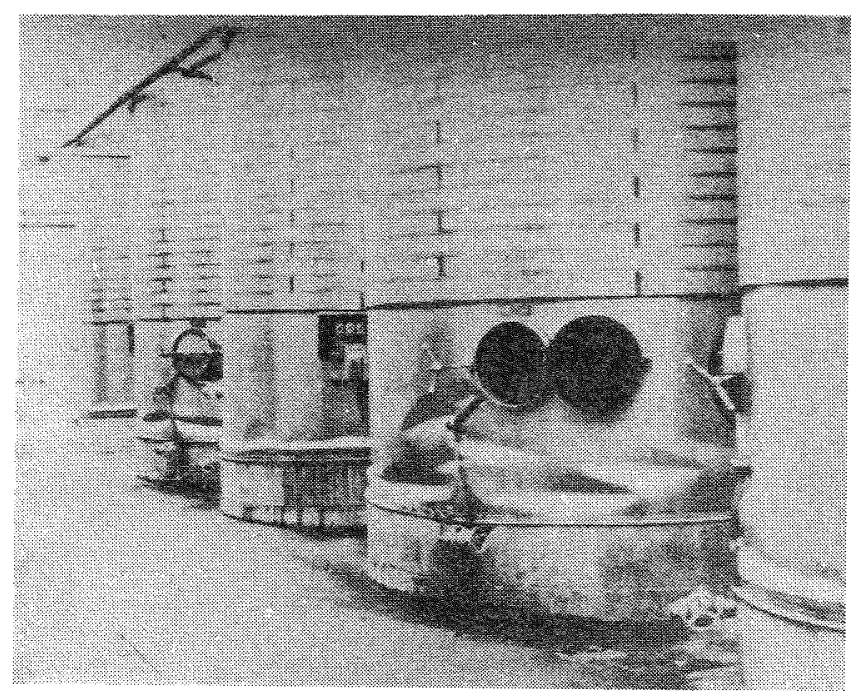

Fig. 2. 'Diamond' Buckling of Stainless Steel Wine Tanks( $\left.{ }^{2}\right)$

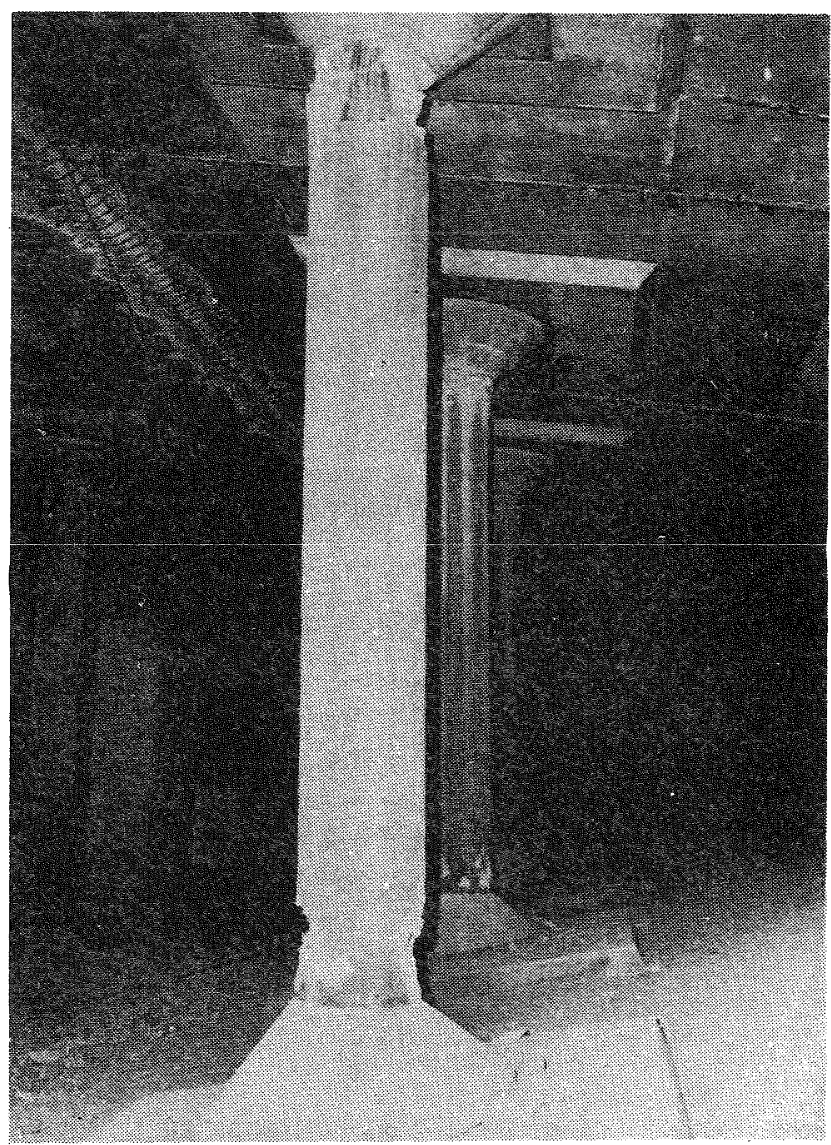

Fig. 4. Damage to Column and Construction Joint of a Large Buried Concrete Reservoir(1,

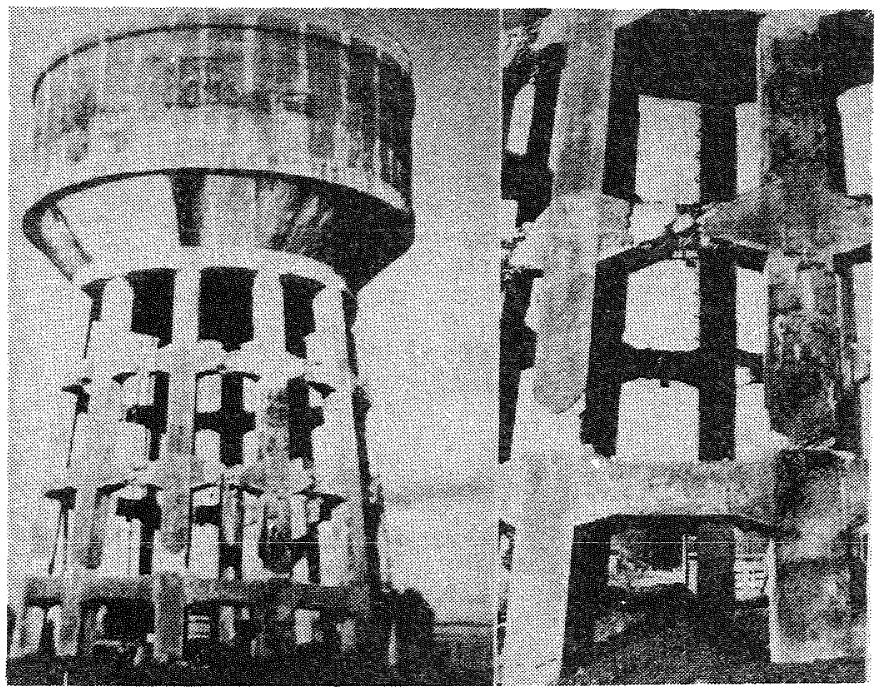

Fig. 3. Damage to Support Frame of Elevated Concrete Reservoir $\left({ }^{3}\right)$

Large Buried Concrete Reservoir 
terms of $p$ values, which may vary with time, rather than by the average return period of design-level ground shaking.

Performance criteria require the tank and any associated bunding to remain serviceable under the design earthquake. Under earthquakes which cause ground shaking more severe than that corresponding to the design earthquake, a designed heirarchy of failure must be established to minimise damage and potential for loss of tank contents.

Section 1 is a simple statement of acceptable risk, and required performance. It contains a total of only seven clauses, but effectively fully defines the design philosophy. Other sections of the report may be considered to represent a 'Means of Compliance' with section 1.

\section{SECTION 2 : DESIGN LOADING}

This section defines the loading on the tank shell and foundations corresponding to the design level earthquake. The loading is a function of the mass of the tank, impulsive and convective masses representing the fluid, and earthquake accelerations derived from a response spectrum. Effects of both horizontal and vertical ground acceleration are considered, as are the influence of tank and foundation flexibility.

Section 2 is the longest section of the report, and the commentary to the section contains extensive information in the form of design aids. The provisions of this section for horizontal response are based on the mechanical spring-mass analogy developed by Graham and Rodriguez(14) Jacobsen (15) and Housner(11) for rigid tanks, and modified by Haroun and Housner (16) and veletsos(13) for flexible tanks. In the spring-mass analogy, a proportion of the mass of the fluid contents is considered to act as though rigidly linked to the tank walls, with the remainder of the fluid mass being divided into a series of submasses, each flexibly attached to the tank walls, and each representing a different antisymmetric slosh mode of the fluid in the tank.

In practice, seismic forces on the tank walls can be found with adequate accuracy from the response of the inertia mode and the first slosh mode. Thus for rigid tanks, the simulation of Fig. 5(a) applies, where $\mathrm{m}_{O}$ and $\mathrm{m}_{1}$ are the inertia and first-mode masses, acting at heights $h_{0}$ and $h_{l}$ above the base. For flexible tanks, a category which will include most steel tanks, the inertia mass $m_{0}$ is divided into two sub-masses $m_{r}$ and $m_{f}$, acting at heights $h_{r}$ and $h_{f}$, representing the proportion of tank contents that continue to act as though rigidly attached to the tank floor, and the proportion that interacts with the lateral flexibility of the tank walls.

Design aids to calculate the masses $\mathrm{m}_{\mathrm{o}}$ $\mathrm{m}_{\mathrm{f}}, \mathrm{m}_{\mathrm{r}}, \mathrm{m}_{\mathrm{l}}$ and heights $\mathrm{h}_{\mathrm{O}}, \mathrm{h}_{\mathrm{f}}, \mathrm{h}_{\mathrm{r}}, \mathrm{h}_{1}$ are available in the literature for cylindrical tanks with vertical axis, and for rectangular tanks. These are reproduced for convenience in the recommendations.

The periods of the various modes represented by the spring-mass analogy may be calculated from data available in the literature, and reproduced in the document. However, this data relates to rigid foundation conditions, and modifications are necessary to account for the influence of foundation flexibility. The effects of foundation flexibility are particularly significant for the inertial mode of response, for which the assumption of rigid foundations may be significantly nonconservative. Equations for period shift, which is related to the relative stiffness of tank and foundation, and increased damping associated with the inertia modes, are included in the recommendations.

Having found the masses and periods associated with the horizontal modes of response, the total horizontal seismic force $Q_{i}$ associated with a particular mode $i$ of

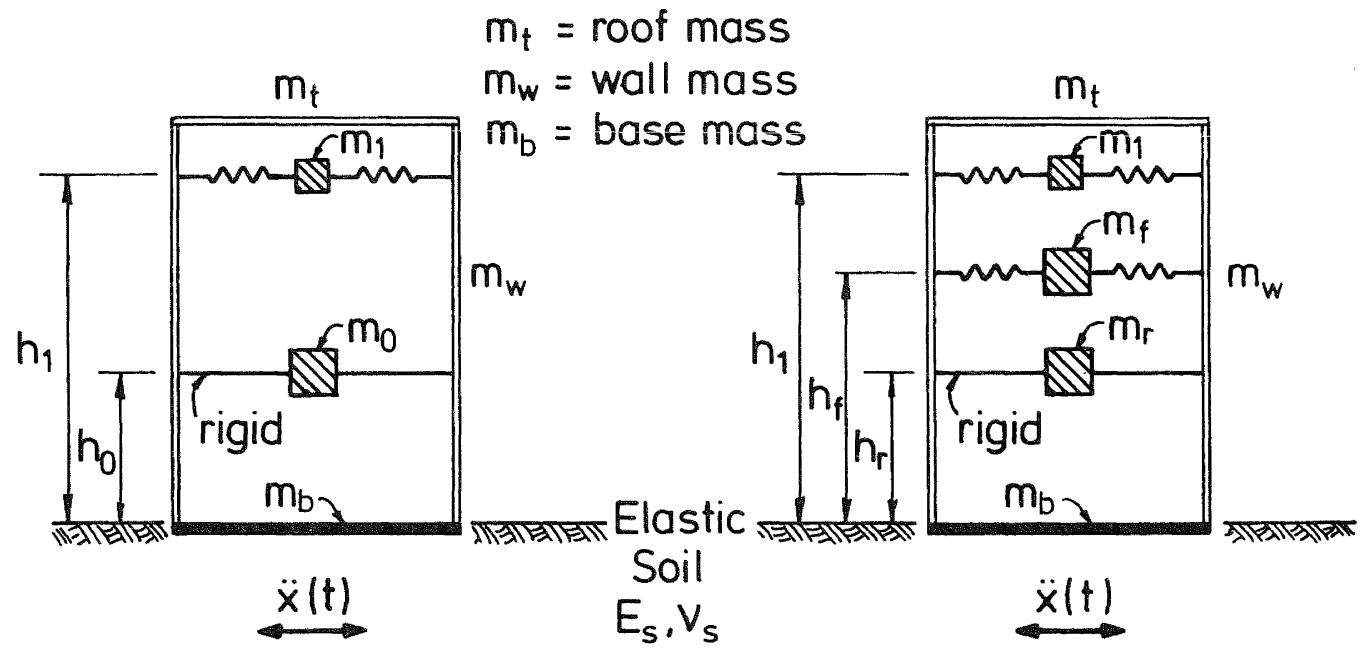

(a) Rigid Tank

(b) Flexible Tank 
response is calculated from the expression

$$
Q_{i}=C_{h(T)} m_{i} g
$$

where

$$
C_{h(T)}=\alpha \cdot \beta A_{h(T)}{ }^{A_{p}}
$$

and

$$
\alpha=\text { peak horizontal acceleration }
$$
coefficient for annual probability of exceedence of $\mathrm{p}=0.01$

$\beta=$ geographic coefficient to represent regional seismicity

$\mathrm{A}_{\mathrm{h}(\mathrm{T})}=$ ordinate of the normalised horizontal acceleration response spectrum for period $T$ of mode $i$

$A_{p}=$ probability factor for design level of probability of exceedence $\left(A_{p}=1\right.$ for $p=0.01$ )

$m_{i}=$ equivalent mass of tank and contents responding in the dynamic mode considered.

Note that the product $\alpha \beta A_{p}$ represents the expected peak ground acceleration at the site for the design-level earthquake.

There is considerable debate currently in New Zealand relating to the appropriate response spectra to reflect New Zealand seismicity. To a large extent the debate is a result of the total lack of near-field strong motion accelerograph records for medium to large earthquakes $(M>6)$. As a consequence, seismology models for New
Zealand rely extensively on foreign data modified by what little local data that is available (17). As this debate has not been resolved at the time of writing this paper, or finalising the Society's recommendations, values for $\alpha, \beta, A_{p}$ and $A_{h}(T)$ are not included in the 'code' part of section 2. The commentary, however, contains interim data that are expected to be conservative. Examples of $A_{h}(T)$ and $A_{p}$ are included in Fig. 6. For the most seismic regions of New Zealand, a value of $\alpha=0.35$ is recommended. Note that the spectra of Fig. 6(a) include curves for damping of $0.5 \%$ as well as $5 \%$, and extend to periods of $10 \mathrm{sec}$. The low damping and high period data are necessary to assess the response of the slosh mode, which will typically have a period in the range $2<T_{1}<10 \mathrm{sec}$, and will have much lower damping than the 5\% 10\% level commonly assumed for elastic structural response.

A similar approach to that outlined above is included for vertical ground accelerations. Although vertical accelerations have traditionally been ignored in most seismic design applications, there is evidence that the effects may be quite significant for steel storage tanks. It is possible to excite a 'breathing' mode involving flexibility of the tank walls, which results in amplification of the effects of the vertical ground accelerations. It is felt that high vertical response accelerations have a major influence in the formation of the 'elephants foot' buckling of Fig. 1. Figure 7 shows the spring-mass models representing vertical response for both rigid and flexible-wall tanks. In both cases, the influence of foundation

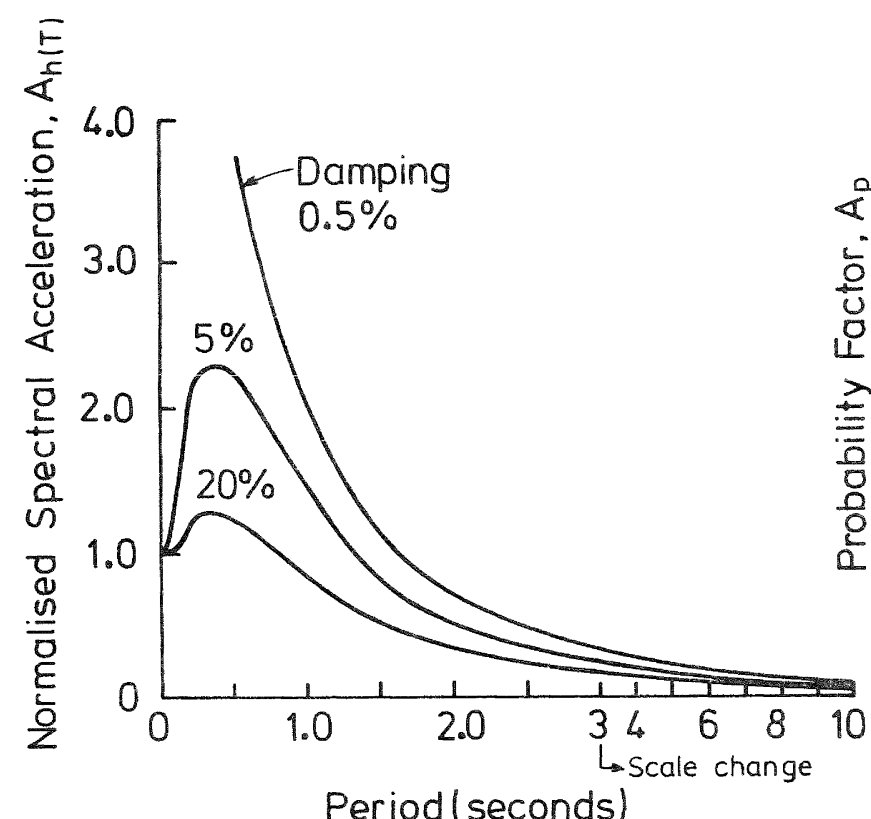

(a) Normalised Response Spectrum

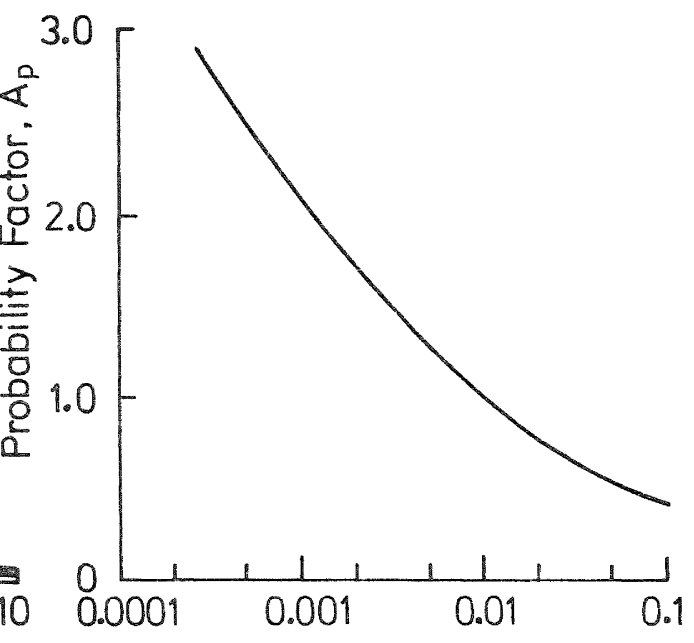

Annual Probability of Exceedence,p (b) Probability Factor 


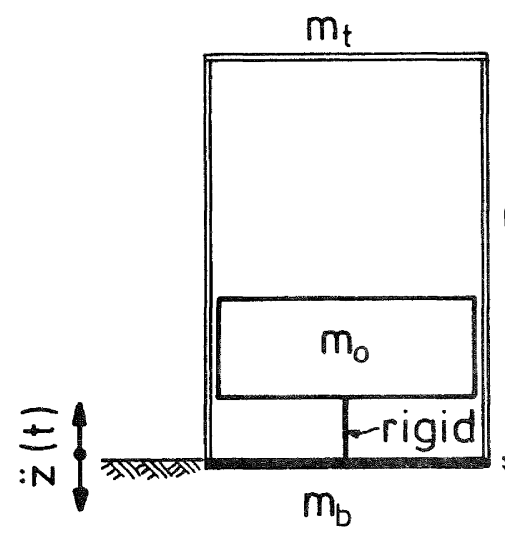

(a) Rigid Tank $m_{t}=$ roof mass

$m_{\mathrm{w}}=$ wall mass

$m_{b}=$ base mass

$m_{w}$

Elastic तात्राधात्रात

Soil

$E_{s}, V_{s}$

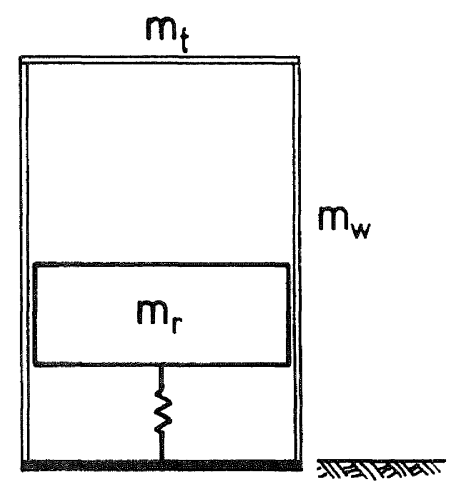

$m_{b}$

(b) Flexible Tank

\section{FIG. 7 SPRING-MASS ANALOGY FOR VERTICAL EARTHQUAKE RESPONSE}

flexibility must be considered when assessing the vertical response period and corresponding level of damping.

Although much of section 2 relates to cylindrical or rectangular tanks, with vertical axes, data are included for other tank shapes, including horizontal cylinders, spheres and cones. Granular materials are covered by assuming that slosh modes are inhibited, and that response is in the inertia mode.

\section{SECTION 3 : DESIGN ACTIONS}

As well as defining the basic earthquake loading, Section 2 gives data on the dimensionless pressure distributions resulting from the horizontal and vertical seismic loading. These data are manipulated in Section 3 to produce dimensionless design charts for hoop tension and bending moment. Most detailed design data is given for circular tanks with vertical axis, for which design charts have been plotted for impulsive-

\section{IMPULSNE PRESSURE}

$H: R=0.50$
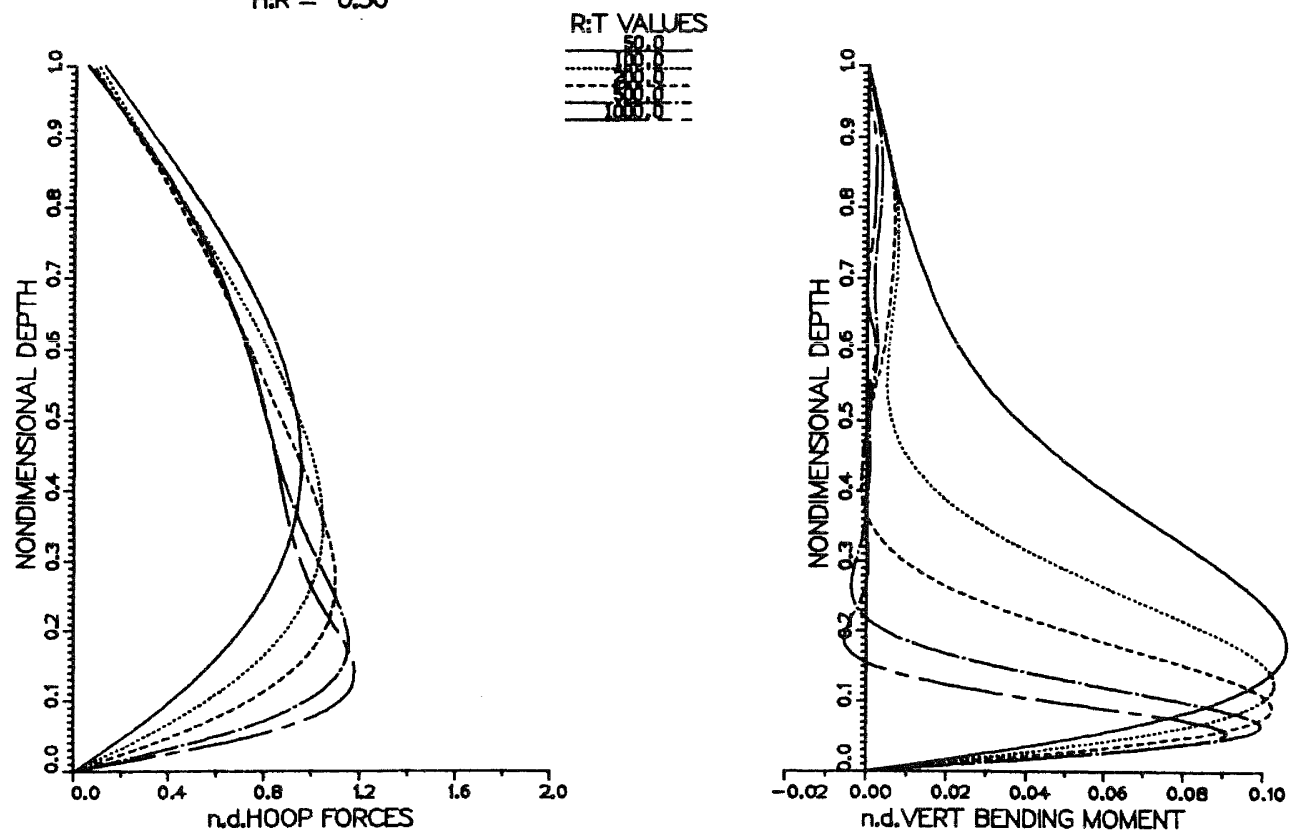
rigid, impulsive-flexible, convective (slosh) and hydrostatic pressure distributions. Figure 8 shows an example for impulsiverigid pressure. Data are related to the tank radius $R$, height $H$ and wall thickness t. Actual hoop force $\mathrm{N}$ and vertical bending moment $\mathrm{M}_{Z}$ are found from the dimensionless values $\mathrm{N}_{\phi}$ ' and $\mathrm{M}_{\mathrm{z}}$ ' given in Fig. 8(a) and (b) respectively by the relationships.

$$
\begin{aligned}
& N_{\phi}=N_{\phi}^{\prime} R p \\
& M_{z}=M_{z}^{\prime} \text { Rpt }
\end{aligned}
$$

where $p$ is a representative pressure; in this case $p$ is the pressure at the tank base on the diameter parallel to the direction of horizontal ground acceleration.

The design charts of Section 3 have been specially produced for the document by an extensive set of computer analyses, and provide designers with detailed design information without the need for complex analyses.

Section 3 also defines how stresses resulting from impulsive-rigid, impulsiveflexible and convective load should be combined, and specifies a square Root of Sum of Squares Method (SRSS). Stresses resulting from combined horizontal and vertical response are also combined by an SRSS approach to account for the low probability of simultaneous peak response.

A further section in section 3 provides guidance for predicting behaviour of unanchored tanks where the design overturning moment exceeds the restoring moment. Under these circumstances part of the tank base will uplift, causing increased axial compressive stress in the she11, and tension stresses in the tank base. The mechanism of tank uplift is complex and not completely understood. The method adopted in the Recommendations is a modified version of a method described by Clough(18), and requires balancing the overturning moment Mor, which is based on the response of an equivalent anchored tank, by the action of three forces, $W_{S}, W_{f}$ and $W$ forming $M_{R}$, as shown in Fig. 9, and defined by Eqn. 5 :

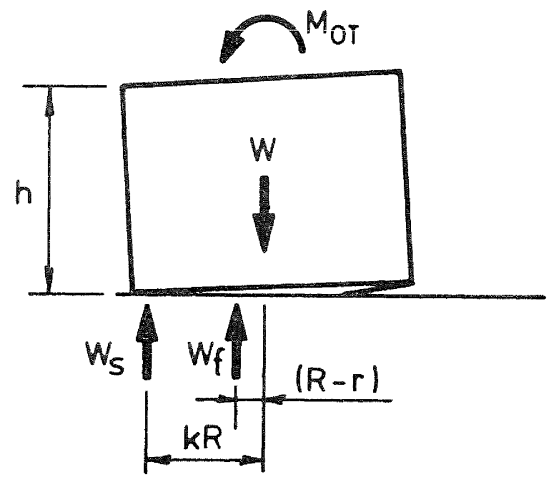

ELEVATION

$$
\mathrm{M}_{\mathrm{R}}+\mathrm{W}_{\mathrm{S}} \mathrm{KR}+\mathrm{W}_{\mathrm{f}}(\mathrm{R}-\mathrm{r})
$$

where $W=$ total weight of fluid, $W_{f}=$ weight of fluid supported directly by the foundation over area of base that does not uplift (radius $r$ ), $W_{W}=$ weight of shell and roof. $W_{S}=W+W_{W}-W_{f}$ and $\theta *$ is the halfangle defining the area of shell base in contact with the foundation.

$M_{R}$, the resisting moment is found iteratively by

ii) calculating $\theta *=\arctan \left(\frac{\mu}{1-\mu}\right)$

iii) calculating $k=\frac{2}{\theta *^{2}}(1-\cos \theta *)$

iv) Calculating

$M_{R}=R W\left(k\left(1+\frac{W_{W}}{W}\right)+(1-k) \mu^{2}-\mu^{3}\right)$

Steps (ii) to (iv) are repeated until $\mathrm{M}_{\mathrm{R}}=\mathrm{M}_{\mathrm{OT}}$.

The maximum axial stress in the shell is then computed as

$$
\mathrm{f}_{\max }=\frac{2.5 \mathrm{c} \mathrm{W}_{\mathrm{S}}}{\mathrm{R} \theta^{*} \mathrm{t}}
$$

where $\mathrm{c}=1.0$ for rigid foundations and $\mathrm{c}=0.5$ for flexible foundations.

A method for estimating uplift displacements and base-plate membrane stresses due to uplifting are also included. A similar method to that outlined above is developed for rectangular tanks.

\section{SECTION 4 : DESIGN CRITERIA}

Section 4 defines allowable limits to stresses and deflections calculated in accordance with section 3. The limits of section 4 are intended to ensure that tanks analysed in accordance with sections 2 and 3 , and complying with these limits, will satisfy the performance criteria of section 1 .

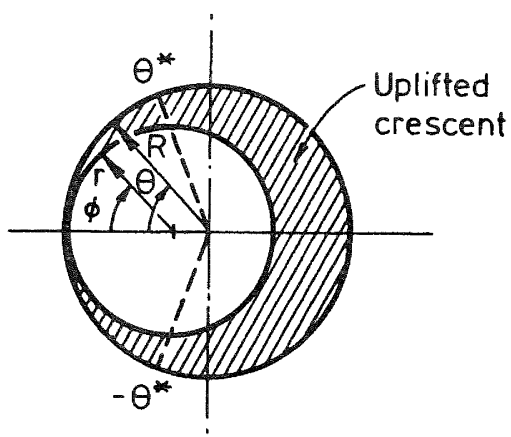

PLAN 
For steel tanks an ultimate load combination of

$$
U=1.0 D+1.0 L_{0}+E
$$

is specified, where $\mathrm{D}$ denotes tank dead load, $L$ denotes $l$ ive load, and $E$ denotes resultant earthquake actions calculated in accordance with Sections 2 and 3 . Note that the load factor on Dead and Live Load is taken as 1.0 in all cases as effects of vertical seismic accelerations are directly included in the earthquake load $\mathrm{E}$.

For concrete tanks, elastic workingstress design to specified stress limits is generally required, in accordance with the 'Alternative' Loading combination:

$$
A=1.0 \mathrm{D}+1.0 \mathrm{~L}_{\mathrm{O}}+0.8 \mathrm{E}
$$

The Elastic Design approach is specified for concrete tanks in preference to ultimate load design because of difficulties in assessing the relative stiffness, as the ultimate condition is approached, of the membrane action and vertical bending action which act together to support the total load. Although the relative stiffness can be computed relatively convincingly at elastic levels of response, the values so obtained are inappropriate at ultimate. The approach taken has also been adopted by a recent New Zealand Standard for the design of Concrete Structures for the storage of Liquids (19).

A common problem in tank design has been to decide whether or not positive anchorage to the foundation is required, and what are the design anchorage forces when anchorage is provided. Except in the case of small tanks, there is very little chance of a tank overturning in an earthquake. This is because the relative energy
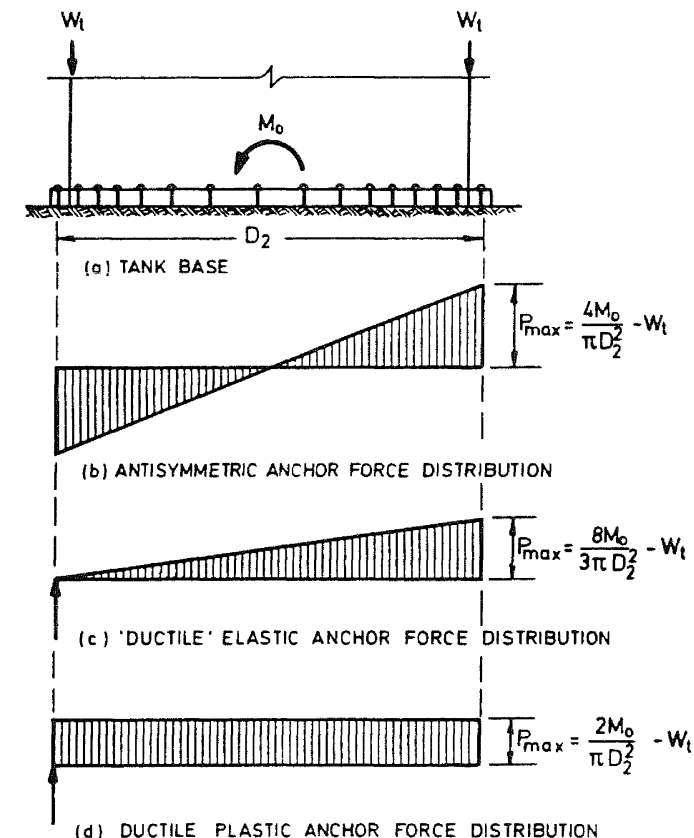

FIG. 10 POSSIBLE ANCHOR FORCE DISTRIBUTION input required to cause overturning increases as the tank size increases. Ishiyama(20) showed that for rigid bodies, overturning could only occur if the peak ground acceleration $\mathrm{a}_{\circ}$ and the peak ground velocity $v_{o}$ exceeded certain values, since the ground acceleration is required to be of a sufficient magnitude to induce rocking and the peak velocity is required to establish sufficient energy input to overturn the body. This approach has been adapted for circular tanks to produce requirements that vertical axis tanks should be anchored to their foundations when

and

$$
\begin{aligned}
& \frac{H}{R}>\frac{2}{\alpha \beta A_{(T)}{ }^{A} p} \\
& R<\left(\alpha \beta A_{p}\right)^{2} \frac{H}{R}
\end{aligned}
$$

Tanks with aspect ratios greater than the limit of Eqn. (13) and with radius less than the limit of Eqn. (14) are potentially susceptible to overturning, and should be anchored to their foundations. Other tanks may be anchored, even though not required by Section 4 , to reduce shell stresses or displacements.

Where positive anchorage is provided, the maximum hold-down force per unit length $P$, is dependent on the ductility of the anchors. For normal anchor bolts, where brittle fracture in a root thread can be expected, the calculation is based on a symmetric distribution of anchor forces as shown in Fig. 10 (b). Thus

$$
P_{\max }=\frac{4 M_{o}}{\pi D_{2}^{2}}-W_{t}
$$

where $W_{t}$ is the vertical load carried by the tank wall per unit circumferential length at the base, and $\mathrm{M}_{\mathrm{O}}$ is the overturning moment. This equation is specified in API-650-E(8) Where the anchors are necked over a reasonable length to a diameter less than the root thread diameter, thus ensuring ductility, the distribution of tie-down force could approach the distributions of Fig. 10 (c) or 10 (d). For this case, Section 4 conservatively adopts the distribution of Fig. 10 (c), resulting in

$$
P_{\max }=\frac{8 \mathrm{M}_{0}}{3 \pi \mathrm{D}_{2}{ }^{2}}-\mathrm{W}_{\mathrm{t}}
$$

Use of Eqn. (16) provides some economic benefit from adopting ductile anchor bolts.

Section 4 contains specific requirements for steel and concrete tanks, separately discussed in brief, below.

\section{Provisions for Steel Tanks}

A significant departure from past practice for tank design has been taken in the approach for allowable stresses in steel tanks. Since Eqn. (11) is an ultimate load equation, and since the design approach is based on probabilistic considerations, allowable stresses are specified with the 
intention of matching as closely as possible the strength of the tank to the loading resulting from the design-level earthquake $(8)$ This differs from, for example, API-650-E (8) whose provisions for allowable stress include 'factors of safety'.

For cylindrical steel tanks, the maximum seismic response could be limited by a number of possible failure modes, including elastic or inelastic buckling in membrane compression (which induces the characteristic diamond buckles, buckling in membrane shear, elastic-plastic collapse at the base of the shell wall (inducing the characteristic 'elephants-foot' buckling) and material yield under bending moment or hoop tension. The recommendations in section 4 are based on an extensive review of experimental results, and theories of cylindrical shell buckling, by Rotter(21).

\section{Buckling in Membrane Compression}

The vertical membrane stress to induce buckling in a shell is a function of the internal pressure, the circumferential variation of axial stress, and above all, the relative amplitude of imperfections $(\delta / t)$ in the wall. The effect of imperfections (radial errors in wall position) is to decrease the buckling stress to a fraction of the classical 'perfect shell' buckling stress $\mathrm{f}_{\mathrm{Cl}}$, given by Eqn. (19). Internal pressure decreases the effective imperfection amplitude, hence increasing the buckling stress. Circumferential variation of axial stress reduces the probability of coincidence of the maximum stress and the maximum imperfection, again increasing the buckling stress. Thus the buckling load associated with membrane compression induced by bending exceeds that where the compression is induced by axial load. However, in both cases (internal pressure, and bending) it appears that the classical buckling stress is an upper limit.

$$
\frac{f_{m}}{f_{c l}} \leq 0.19+0.81 \frac{f_{p}}{f_{c l}}
$$

where

$$
\begin{gathered}
\left.f_{p}=f_{C l} \sqrt{\left(1-\left(1-\frac{\bar{p}}{5}\right)^{2}\left(1-\left(\frac{f_{O}}{f_{C l}}\right)^{2}\right.\right.}\right) \leq f_{C l} \\
f_{C l}=0.6 E \frac{t}{R} \\
\bar{P}=\frac{p R}{t f_{C l}} \leq 5
\end{gathered}
$$

For

$$
\left(\lambda^{2}=\frac{f_{y}}{\sigma f_{C l}}\right) \leq 2: \quad f_{0}=f_{y}\left(I-\frac{\lambda^{2}}{4}\right)
$$

For

$$
\left(\lambda^{2}=\frac{f_{y}}{\bar{\sigma}_{\mathrm{f} l}}\right) \geq 2 ; \quad \mathrm{f}_{\mathrm{O}}=\bar{\sigma}_{\mathrm{fl}}
$$

$\left.\left.\bar{\sigma}=1-\psi\left(\frac{\delta}{t}\right)\left[\left(1+\frac{2}{\psi(\delta / t}\right)\right)^{\frac{1}{2}}-1\right)\right]$

and $(\delta / t)$ is the ratio of maximum imperfection amplitude to wall thickness. In Eqn. (22) $\psi=1.24$ for membrane compression buckling.

Equations (17) to (22) reflect these influences. The allowable stress is related to the classical buckling stress given by Eqn. (19). The reduction from this stress level due to initial imperfections for unpressurised tanks subjected to axial compression is given by Eqns. (21) and (22). For buckling stresses higher than $0.5 \mathrm{f}_{\mathrm{y}}$, (i.e. relatively thick-walled tanks) the buckling is essentially inelastic, and Eqn. (2la) governs. For lower buckling stresses (relatively thin-walled tanks) Eqn. (2lb) governs.

Equation (18) expresses the increase in buckling stress due to internal pressure (23), expressed in terms of the nominal hoop stress ratio $\bar{p}$ given by Eqn. (20).

Equation (17) expresses the increase in buckling stress due to the axial stress being induced by bending, rather than axial loading(24). As this is primarily the case for seismically induced membrane compression, it is appropriate to include in these stress criteria. Note that the maximum allowable stress that can result from Eqns. (17) to (22) is the classical buckling stress $\mathrm{f}_{\mathrm{Cl}}$. Generally the level is much lower.

Figure 11 compares the membrane compression buckling stresses for normal quality construction with the classical buckling equation. The influence of a moderate hoop tension of $100 \mathrm{MPa}$ in increasing the buckling stress is very evident, particularly at high $R / t$ values. The influence of bending compression, compared with uniform compression is also significant, but the influence decreases as the internal pressure increases.

For comparison, the buckling stress equation of API-650-E for zero internal pressure has been included. To convert from working stress to ultimate load levels, the API-650 stresses have been increased by $25 \%$.

\section{Elastic-Plastic Collapse}

Towards the bottom of the tank, the steel is subjected to a biaxial stress state consisting of hoop tension and (in the worst case) vertical compression, as shown in Fig. 12. Radial deformations under internal pressure create additional eccentricity, tending to induce the commonly observed 'elephants foot' buckling. The following equation, developed by Rotter (25) gives an accurate assessment of the stress required to initiate elastic-plastic collapse, and is specified in the Recommendations. 


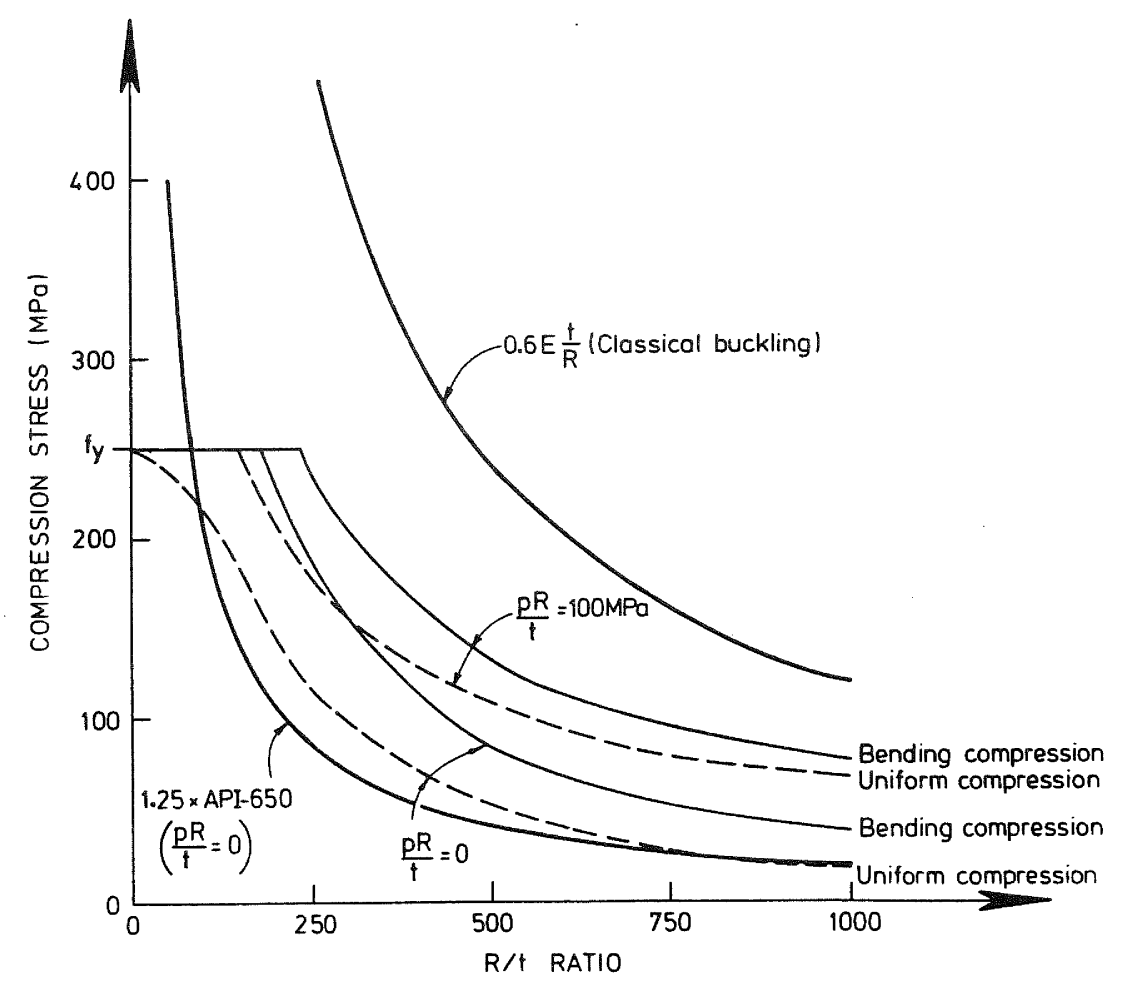

FIG. 11 MEMBRANE COMPRESSION BUCKLING STRESSES FOR NORMAL QUALITY CONSTRUCTION ( $\mathrm{f} y=250 \mathrm{MPa}$ )

$$
\begin{gathered}
f_{m} \leq f_{c 1}\left[1-\left(\frac{p R}{t f_{y}}\right)^{2}\right]\left(1-\frac{1}{1.12+s^{1.5}}\right) \\
\cdot\left[\frac{s+f_{y} / 250}{s+1}\right]
\end{gathered}
$$

where

$$
s=\frac{R / t}{400}
$$

The influence of internal pressure in Eqn. (23) is to reduce the maximum compression stress that can be sustained.

Figure 13 compares the flexural compression stresses required to induce failure of a pressurised tank by elastic buckling or by elastic-plastic collapse. Except for thick walled tubes, elastic buckling is critical for low values of the membrane circumferential stress. As this stress increases above about $100 \mathrm{MPa}$, elastic-plastic collapse becomes the dominant failure case.

Special attention is given to the design criteria for base plates of unanchored tanks. Under the tank uplifting condition, the membrane tension induced in the uplifting portion of the base plate induces a circumferential ring compression reaction. The biaxial stress state reduces the effective yield stress. In the absence of more detailed analysis, it is recommended that a conservative radial effective stress of $0.6 f_{y}$ be used. Base plate design is limited by aximum allowable plastic strain of 0.05 at the plastic hinge forming in the base plate adjacent to the wall. Guidance is given on estimating the maximum plastic strain, but it is emphasised that the calculation methods are somewhat crude.
It should be noted that the above recommendations for steel tanks were adopted at a late stage of the study groups deliberations. In a preliminary report of the study aroup (26) an ealier set of criteria, which do not reflect the two different possible modes of failure, were presented.

\section{Provisions for Concrete Tanks}

Allowable stresses in reinforced and prestressed tanks under the 'Alternative' Load combination are based on the values specified in NZS 3106 (19). Because of the transitory and infrequent nature of the loading, high stress levels are permitted,

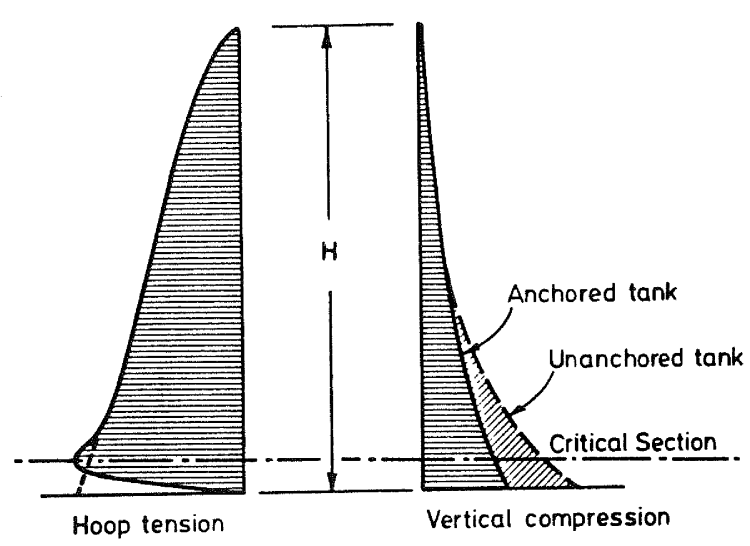

FIG. 12 MEMBRANE FORCES IN TANK WALL 


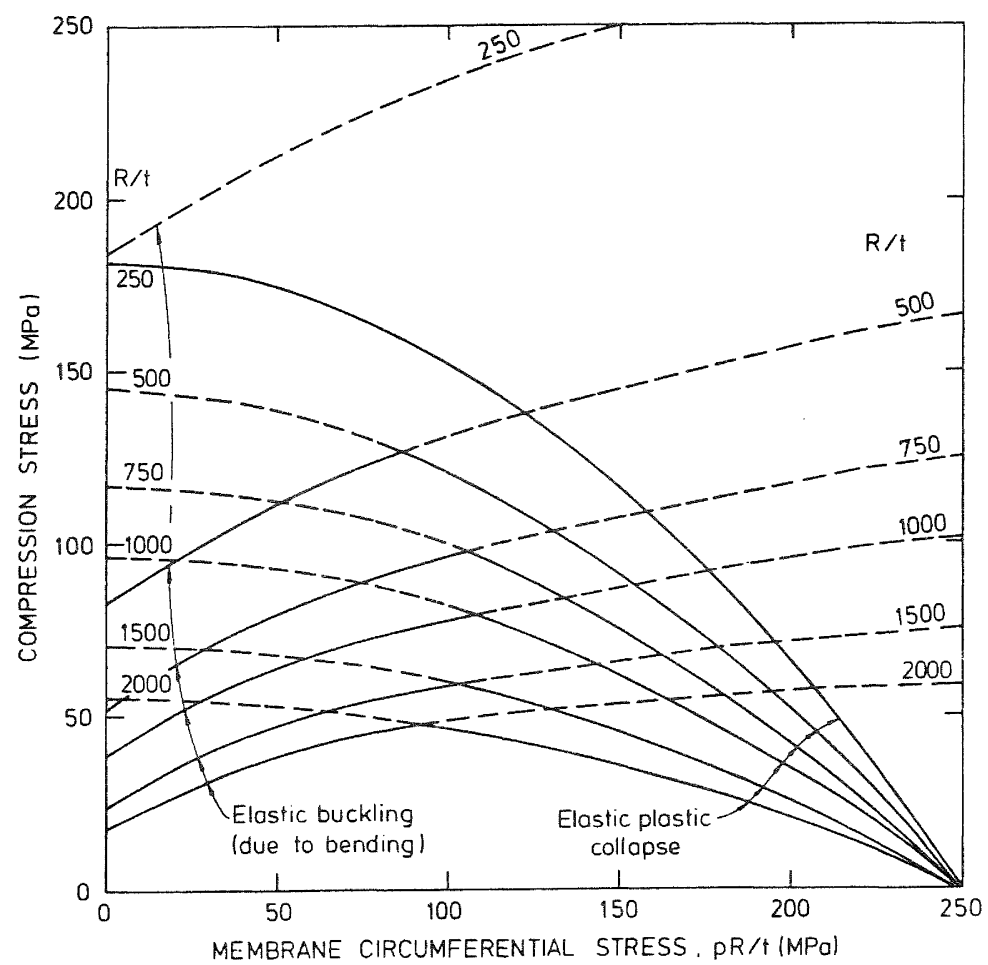

FIG. 13 COMPARISON OF ELASTIC BUCKLING AND ELASTIC-PLASTIC COLLAPSE STRESSES ( $f y=250 \mathrm{MPa}$, NORMAL QUALITY CONSTRUCTION)

with maximum compressions up to $0.6 f^{\prime}$, where $f_{C}^{\prime}$ is the cylinder compression strength, and maximum tensions in prestressed concrete up to $0.5 \sqrt{f^{T}}$. Out of plane shear stresses are regulated by limits to principal tension stress.

\section{SECTION 5 : FOUNDATIONS}

This section is necessarily less specific than the former sections, because of the complexity of Geotechnical aspects of tank design, and a consequent reluctance of Geotechnical Engineers to provide specific and detailed design data in a code format. New Zealand designers will be familiar with the controversy associated with unsuccessful attempts in the past to formulate a general Foundation Design Code. Section 5 places particular importance on the need for expert Geotechnical advice for major installations. The section discusses Site Investigation requirements, Foundation Evaluation, with special attention drawn to erodible soils, liquefiable soils, collapsible soils and sensitive soils, Foundation Analysis, with suggested factors of safety for slope stability, bearing capacity, liquefaction and base sliding, and Foundation Details. This last subsection discusses foundation detailing required for ground improvement, pile foundations, foundation drainage, and mounded or buried tanks.

\section{SECTION 6 : DESIGN DETAILS}

The Recommendations are not a design manual, and hence emphasis on design details would be inappropriate. However, it was felt appropriate to draw attention to a small number of design details that have the potential for having a great influence on the performance of tanks under earthquake loading. Aspects relevant to steel tanks include flexible piping connections, reinforced nozzle connections to thin walled tanks, displacement tolerance of floating roofs, frangible joints between shell and roof for fixed-roof tanks, and base anchorage details. Methods for providing membrane shear transfer between wall and base of concrete tanks are discussed.

\section{APPENDIX : DESIGN EXAMPLES}

To assist designers in using the recommendations, an Appendix is included with detailed design examples relating to

(1) a large circular oil storage tank

(2) a stainless steel wire vat

(3) a prestressed circular concrete reservoir on alluvium site

(4) a rectangular concrete reservoir.

Both rigid and flexible foundation conditions are considered. and the steel tanks are both analysed in the anchored base and uplifting base condition.

\section{CONCLUSIONS}

The Recommendations of the Study Group of the New Zealand National Society for Earthquake Engineering, into the Seismic Design of Storage Tanks represent an attempt to present a consistent design approach for tanks of all materials, and to 
cover aspects of seismic loading that have often been ignored. Design criteria and required performance are clearly stated in simple terms. Although most of the provisions have been based on existing published information, it has been necessary to extrapolate in some cases, particularly for tanks of unusual shape.

It is the belief of the Study Group which drafted the Recommendations that the document will result in safe and economic tanks for regions of high seismicity.

\section{ACKNOWLEDGEMENTS}

The full committee of the Study Group included D.C. Hopkins, L. Gaerty, J. Vessey, G. Honey, G. Ramsay and R. Martin as well as the authors of this paper. Full acknowledgement is made of their extensive contribution to the material forming the basis of this paper.

Acknowledgement is also made of the generous financial assistance received from the Heavy Engineering Research Association, the New Zealand Concrete Research Association, Mobil, Caltex, BP, Shell Petrocorp, New Zealand Refining, and the University of Canterbury.

\section{REFERENCES}

(1) Jennings, P.C. (Ed), 'Engineering Features of the San Fernando Earthquake of February 9, 1971', Report EERL 71-02, California Institute of Technoloqy, Pasadena, 1971.

(2) Moore, A.T., 'The Response of Cylindrical Liquid Storage Tanks to Earthquakes', Proc. Int. Conference on Large Earthquakes, Misc. Series No. 5, Royal Society of New Zealand, 1981.

(3) Berg, G.V. and Stratta, J.L., 'Anchorage and the Alaska Earthquake of March 27, 1964', American Iron and Steel Institute, New York.

(4) Kawasumi, H. (ed), 'General Report on the Niigata Earthquake of 1964', Tokyo Electical Engineering College Press.

(5) Steinbrugge, K.V. and Flores, R., Engineering Report on the Chilean Earthquakes of May 1960 - A Structural Engineering Viewpoint', B.S.S.A., Vol. 53, No. 2, 1963.

(6) Priestley, M.J.N. (Ed), 'Seismic Desian of Storage Tanks', New Zealand National Society for Earthquake Engineering, Wellington, 1986.

(7) - , 'Code of Practice for General Structural Design and Design Loadings for Buildings', NZS 4203:1984, Standards Association of New Zealand, 1984.

(8) - 'Welded Steel Tanks for Oil Storage. Appendix E - Seismic Design of Storage Tanks", API-650-E, American Petroleum Institute, Nov. 1980.
(9) - 'Seismic Design of Petrochemical Plants', Ministry of Works and Development Civil Division Publication, Wellington, 1981.

(10) - 'AWWA Standard for Welded Steel Tanks for Water Storage', AWWA-D100, American Waterworks Association, Denver, Colorado.

(11) Housner, G.W., 'The Dynamic Behaviour of Water Tanks', B.S.S.A., Vol. 53, No. 2, 1963.

(12) Berrill, J.B., Priestley, M.J.N. and Chapman, H.E., 'Design Earthquake Loading and Ductility Demand ", Bull. NZNSEE Vol. 13, No. 3, Sept. 1980 . pp. 232-241.

(13) - , 'Guidelines for the Seismic Design of Oil and Gas Pipeline Systems', $\mathrm{ASCE}, 1984,465 \mathrm{pp}$.

(14) Graham, E.W. and Rodriguez, A.M., 'The Characteristics of Fuel Motion Which Affect Airplane Dynamics', West Coast Conference of the Applied Mechanical Division of the Soc. of Mech. Engineers. California, 1952 .

(15) Jacobsen, L.S., 'Impulsive Hydrodynamics of Fluid Inside a Cylindrical Container, and of Fluid surrounding a Cylindrical Pier', B.S.S.A., Vol. 39, No. 3, 1949 .

(16) Haroun, M.A. and Housner, G.W., 'Dynamic Characteristics of Liquid Storage Tanks', Jour. Engineering Mechanics Division, ASCE, Vol. 108, No. EM5, 1982.

(17) Matuschka, T., Berryman, K.R., Oleary, A.J., McVerry, G.H. Mullholland, W.M. and Skinner, R.I., 'New Zealand Seismic Hazard Analysis', Bull. NZNSEE Vol. 18, No. 4, Dec. 1985, pp. 313-222.

(18) Clough, D.P., 'Experimental Evaluation of Seismic Design Methods for Broad Cylinder Tanks', EERC 77/10, University of California, Berkeley, 1977.

(19) - 'Code of Practice for Concrete Structures for the Storage of Liquids', NZS 3106, Standards Association of New Zealand, 1986

(20) Ishiyama, Y., 'Motion of Rigid Bodies and Criteria for Overturning by Earthquake Excitations', Bull. NZNSEE Vol. 17, No. 1, March 1984, pp.24-37.

(21) Rotter, J.M., 'Buckling of GroundSupported Cylindrical Steel Bins Under Vertical Compressive Wall Loads', Proc. Metal Structures Conference, Institution of Engineers, Australia, Melbourne, 1985, pp.112-127.

(22) Koiter, W.T., ' On the Stability of Elastic Equilibrium', (in Dutch), Ph.D. Thesis, Delft University, 1945. 
(23) Trahair, N.S., Abel, A., Ansourian, P., Irving, H.M. and Rotter, J.M.,

'Structural Design of steel Bins for

Bulk Solids', Australian Institute of Steel Construction, 1983.

(24) European Convention for Constructional Steelwork, 'Recommendations for Steel Construction : Buckling of Shells', 2nd Ed., 1983.

(25) Rotter, J.M., 'Local Inelastic Collapse of Pressurised Thin Cylindrical steel Shells Under Axial Compression", Research Report, School of Civil and Mining Engineering, University of Sydney, 1985.

(26) Priestley, M.J.N., Wood, J.N. and Davidson, B.J.,' Seismic Design of Steel Storage Tanks', Proc. Pacific Structural Steel Conference, Auckland, Aug. 1986, Vol. 4, pp. 233-250. 